\title{
ENERGY PERFORMANCE ANALYSIS OF INSULATING WINDOWS
}

FLORIN IORDACHE - Lecturer, PhD, Technical University of Civil Engineering, Faculty of Building Services, e-mail: fliord12@gmail.com

IULIAN CLITA - PhD Student, Technical University of Civil Engineering, Faculty of Building Services, e-mail:ahile2004@yahoo.com

ARTHUR-SEBASTIAN KLEPŞ - PhD Student, Technical University of Civil Engineering, Faculty of Building Services, e-mail:akleps@gmail.com

\begin{abstract}
The present paper thematically fits in the current concern for reducing energy consumption to ensure normal thermal comfort in residential and tertiary building heated spaces. Windows are an important area of the building envelope through which heat dissipates from the interior space to the exterior. As it is known the new insulating window types significantly reduce energy dissipation by both transmission and infiltration. This paper aims to establish the theoretical correlations that exist between different constructive functional parameters of insulating windows, such as gas or gases located between two or three window sheets and low- $\varepsilon$ films to be applied on interior faces of the transparent elements. The theoretical work procedures as well as the tabulated and graphical results regarding the thermal resistances for various insulated window structures are presented. The results are analyzed in comparison with the values contained in the C107 regulation for building heat calculations.
\end{abstract}

Keywords: window insulation, building energy, building thermal rehabilitation, energy performance

\section{Introduction}

The thermal rehabilitation of buildings is currently one of the leading preoccupations of engineers and architects in various fields related to construction.

As one knows one of the measures taken in most situations is to replace old windows with wooden or metal frames with insulated windows able to significantly contribute to reducing building heat consumption during the cold season. Today the insulating windows are characterized by high thermal resistance and by low and controlled infiltration of fresh air.

The goal of this paper is the theoretical analysis on energy performance of modern insulated windows, double and triple glazed, in terms of the heat transmitted through their surface.

The determining parameters for the energy performance were analyzed, i.e.: the distance between the transparent elements, the gas type between the transparent elements and the surface emissivity of the transparent elements. The analysis was performed in different climatic stress situations from the outside environment.

The results are presented numerically and graphically in order to make comparative observations on the importance of the mentioned parameters.

\section{Description of Adopted Theoretical Models}

To establish the thermal behavior in the current operating mode of the rooms, the windows were treated as thermal systems subject to stationary heat transfer. The double glazed window was considered to be composed of two components (the two transparent elements) and the triple glazed window of three transparent elements. Writing the heat balance equations in the stationary regime for each of the transparent elements leads to the mathematical model. A 
detailed presentation of the thermal balance equations for double and triple glazed windows is found in [1]. The desired results based on the mentioned mathematical model refer to:

- Thermal resistance of double and triple glazed windows;

- Heat flux density transmitted through the window from inside towards outside;

- Transparent element temperatures.

Thus for the double glazed window:

- By neglecting the conductive thermal resistances of the transparent elements, the thermal resistance of the window is:

$$
R_{F E}=\frac{1}{\alpha_{i}}+\frac{1}{\alpha_{g}}+\frac{1}{\alpha_{e}}
$$

- Heat flux density:

$$
q=\frac{\theta_{i}-\theta_{e}}{R_{F E}}
$$

- Transparent element temperatures:

$$
\Theta=A^{-1} \cdot B
$$

where:

$$
\Theta=\left(\begin{array}{l}
\theta_{1} \\
\theta_{2}
\end{array}\right)
$$

temperature numbering for the transparent elements was made from outside towards inside and:

$$
A=\left(\begin{array}{cc}
\alpha_{e}+\alpha_{g} & -\alpha_{g} \\
-\alpha_{g} & \alpha_{i}+\alpha_{g}
\end{array}\right) \quad \text { and } \quad B=\left(\begin{array}{c}
\alpha_{e} \cdot t_{e} \\
\alpha_{i} \cdot t_{i}
\end{array}\right)
$$

and:

$$
\alpha_{g}=\frac{1}{2} \cdot \alpha_{c}+\alpha_{r}
$$

For the triple glazed window:

- the thermal resistance of the window:

$$
R=\frac{1}{\alpha_{e}}+\frac{1}{\alpha_{g 12}}+\frac{1}{\alpha_{g 23}}+\frac{1}{\alpha_{i}}
$$

- Transparent element temperatures:

where:

$$
\Theta=A^{-1} \cdot B
$$

$$
A=\left(\begin{array}{ccc}
\alpha_{e}+\alpha_{g 12} & -\alpha_{g 12} & 0 \\
-\alpha_{g 12} & \alpha_{g 12}+\alpha_{g 23} & -\alpha_{g 23} \\
0 & -\alpha_{g 23} & \alpha_{g 23}+\alpha_{i}
\end{array}\right) \quad \text { and } \quad B=\left(\begin{array}{c}
\alpha_{e} \cdot t_{e} \\
0 \\
\alpha_{i} \cdot t_{i}
\end{array}\right)
$$


and:

$$
\begin{aligned}
& \alpha_{g 12}=\frac{1}{2} \cdot \alpha_{c 12}+\alpha_{r 12} \\
& \alpha_{g 23}=\frac{1}{2} \cdot \alpha_{c 23}+\alpha_{r 23}
\end{aligned}
$$

Equation (6) in the double glazed window case and equations (11) and (12) in the triple glazed window case allow the evaluation of heat transfer coefficients between the transparent elements, which have a high enough importance on the thermal resistance of the window and thus on the dissipated heat flow. As we can see, the heat transfer coefficient between the transparent elements depends on the convective heat transfer coefficient and the radiant heat transfer coefficient between the transparent elements.

To evaluate the two heat transfer coefficients between the transparent elements, appropriate criteria relations for free convection in confined spaces and for radiant heat transfer between parallel flat surfaces were used.

Thus to evaluate the convective heat transfer coefficient the next relations were used:

$$
\begin{aligned}
& \alpha_{c v}=\lambda \cdot\left(\frac{1}{\delta}+\frac{R a}{720} \cdot \frac{1}{h}\right)_{\text {if }} R a<500 \cdot \frac{h}{\delta} \\
& \text { A. } \\
& \text { B. } \alpha_{c v}=\frac{0.42}{h^{0.33}} \cdot \frac{\lambda}{\delta^{2}} \cdot R a^{0.25} \cdot \operatorname{Pr}^{0.012} \text { if } 10^{4}<R a<10^{7} \text { and } 10<\frac{h}{\delta}<40 \\
& R a=9.81 \cdot \frac{\delta^{3}}{v \cdot a} \cdot \frac{\theta_{1}-\theta_{2}}{\theta_{1}+\theta_{2}+2 \cdot 273.15}, \operatorname{Pr}=\frac{v}{a} \text { and } a=\frac{\lambda}{\rho \cdot c}
\end{aligned}
$$

where:

$$
\begin{aligned}
& G r \text { - dimensionless Grashof number; } \\
& \mathrm{Pr} \text { - dimensionless Prandtl number; } \\
& R a \text { - dimensionless Rayleigh number. }
\end{aligned}
$$

As $R a=G r \cdot \operatorname{Pr}$, Ra expression in relation (15) has been established by us for the analyzed practical cases.

To assess the radiation heat transfer coefficient the next relations were used:

$$
\alpha_{r}=\varepsilon \cdot C_{0} \cdot\left[\Theta_{1}^{2}+\Theta_{2}^{2}\right] \cdot\left(\Theta_{1}+\Theta_{2}\right)
$$

where:

$$
\begin{aligned}
\Theta 1 & =\theta 1+273.15 \\
\Theta 2 & =\theta 2+273.15 \\
\mathrm{C} 0 & =5.67 \cdot 10-8-\text { Stefan-Boltzmann constant (W/m2.K4); } \\
\varepsilon= & \frac{1}{\frac{1}{\varepsilon_{1}}+\frac{1}{\varepsilon_{2}}-1}
\end{aligned}
$$


From the corresponding relations for the evaluation of the convective heat transfer coefficient between the transparent elements and also the radiant heat transfer coefficient between these elements, we can see that their values depend on the unknown temperature values of the transparent elements. Thus direct computing relations of these temperatures (3) for the double glazed window and (8) for the triple glazed window, should use at beginning some initial values for the two mentioned coefficients, values to be updated after each application of relations (3) and (8) until the error may be considered to be sufficiently small. That was how we proceeded in order to obtain concrete values on: the thermal resistance of the window, the heat flux density transferred and the actual values of the transparent element temperature.

\section{Presentation and Analysis of Results}

A series of new construction cases of insulated windows with two and three transparent elements were analyzed as described. We refer to:

a. distance between the transparent elements;

b. gas nature of the transparent elements;

c. surface emissivity of the transparent elements.

Another parameter that was taken into consideration in the analysis was the outside ambient temperature, which is not a characteristic window element.

The distance between the transparent elements results as a value $\delta=0.02 \mathrm{~m}$ that leads to optimal window performance values; in this paper we illustrate this statement graphically.

For the gas nature between the transparent elements, the situations when air, argon and krypton exist were analyzed.

For surface emissivity of the transparent elements both cases in which they are equipped with emissivity reduction films were analyzed as well as the cases when they are not equipped with such films. If the surface is not equipped with emissivity reduction film, its value was considered 0.9 and if the surface is equipped with emissivity reduction film, its value was considered 0.1.

For the outdoor temperature the following situations were considered:

$$
t_{e}=-15^{\circ} \mathrm{C}, t_{e}=-10^{\circ} \mathrm{C}, t_{e}=-5^{\circ} \mathrm{C}, t_{e}=0{ }^{\circ} \mathrm{C}, t_{e}=+5^{\circ} \mathrm{C}, t_{e}=+10^{\circ} \mathrm{C} \text {. }
$$

We expect that outdoor temperature does not influence much the thermal resistance value of the windows, but the heat flux density and the transparent element temperature values will of course be sensibly affected.

As seen from those things presented in the previous chapter, to evaluate the convective heat transfer coefficients between transparent elements it is necessary to know more characteristic parameters of the gas that fills the space between transparent elements. We refer to gas density, thermal conductivity, specific heat and kinematic viscosity of the gas. For the undertaken analysis the following set of values was used:

- air

- Thermal conductivity: $\lambda=0.025 \mathrm{~W} / \mathrm{m} . \mathrm{K}$;

- Density: $\rho=1.20 \mathrm{~kg} / \mathrm{m}^{3}$;

- Specific heat: $\mathrm{c}=1004 \mathrm{~J} / \mathrm{kg} . \mathrm{K}$;

- Kinematic viscosity: $v=15.11 \cdot 10-6 \mathrm{~m}^{2} / \mathrm{s}$.

- $\operatorname{argon}$

- Thermal conductivity: $\lambda=0.017 \mathrm{~W} / \mathrm{m} . \mathrm{K}$;

- Density: $\rho=1.7 \mathrm{~kg} / \mathrm{m}^{3}$; 
- Specific heat: c $=520 \mathrm{~J} / \mathrm{kg} . \mathrm{K}$;

- Kinematic viscosity: $v=13.11 \cdot 10-6 \mathrm{~m}^{2} / \mathrm{s}$.

- krypton

- Thermal conductivity: $\lambda=0.009 \mathrm{~W} / \mathrm{m} . \mathrm{K}$;

- Density: $\rho=3.56 \mathrm{~kg} / \mathrm{m}^{3}$;

- Specific heat: $\mathrm{c}=248 \mathrm{~J} / \mathrm{kg} . \mathrm{K}$;

- Kinematic viscosity: $v=7.02 \cdot 10-6 \mathrm{~m}^{2} / \mathrm{s}$.

To get an overview of the results we present graphically some of their values obtained for representative situations characterized by fixed values of other important parameters.

We will first review the results for the double glazed window:

A. Double glazed window: Gas $=$ Air, $\delta=0.02 m ; \varepsilon_{1}=\varepsilon_{2}=0.9$

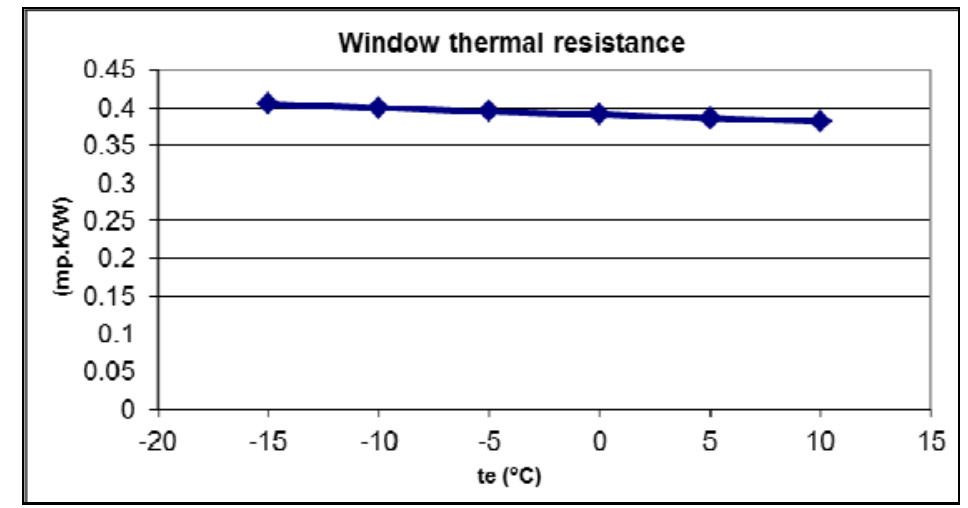

Fig. 1

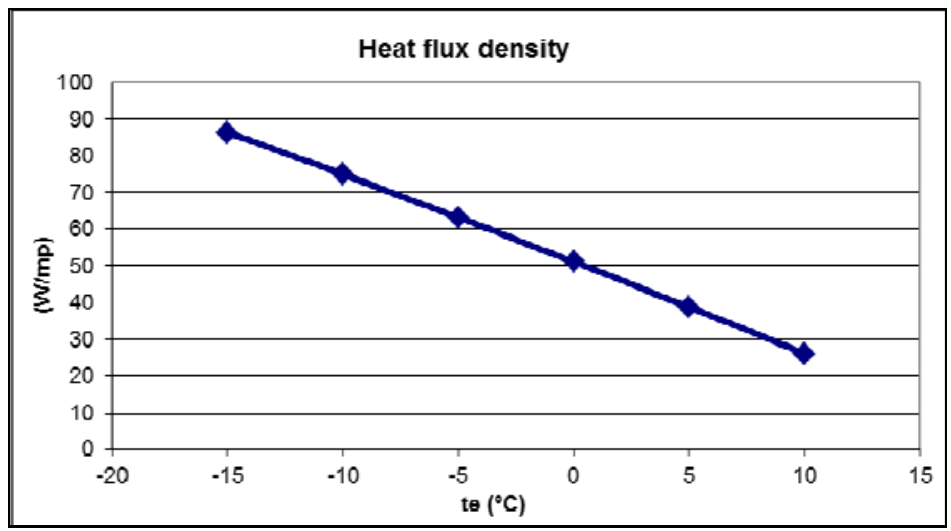

Fig. 2

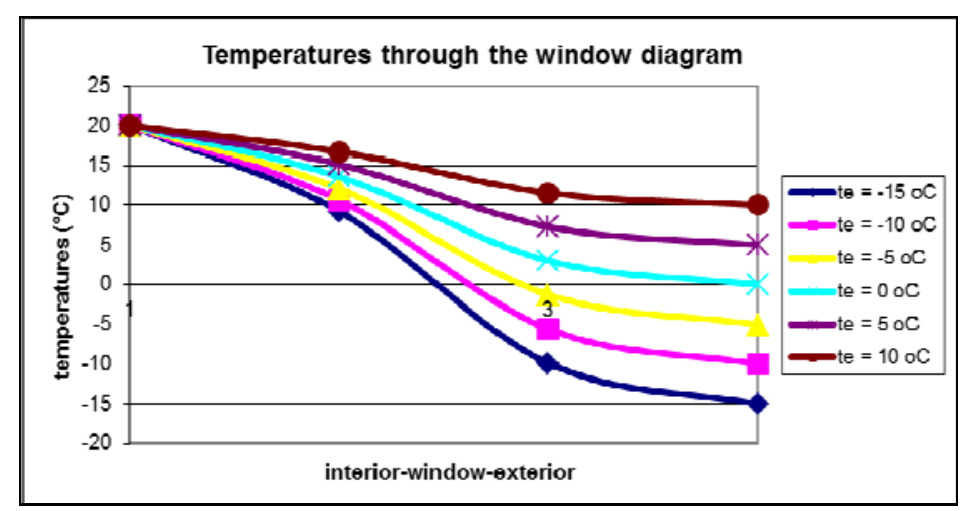

Fig. 3 
The presented results highlight the thermal resistance of the double glazed window in the specified case with a value of approx. $0.4 \mathrm{~m}^{2} . \mathrm{K} / \mathrm{W}$, the earlier remarks made before on its consistency, in concordance with the outdoor temperature, being certified.

B. Double glazed window: Gas $=$ Krypton, $\delta=0.02 m ; \varepsilon_{1}=0.9, \varepsilon_{2}=0.1$

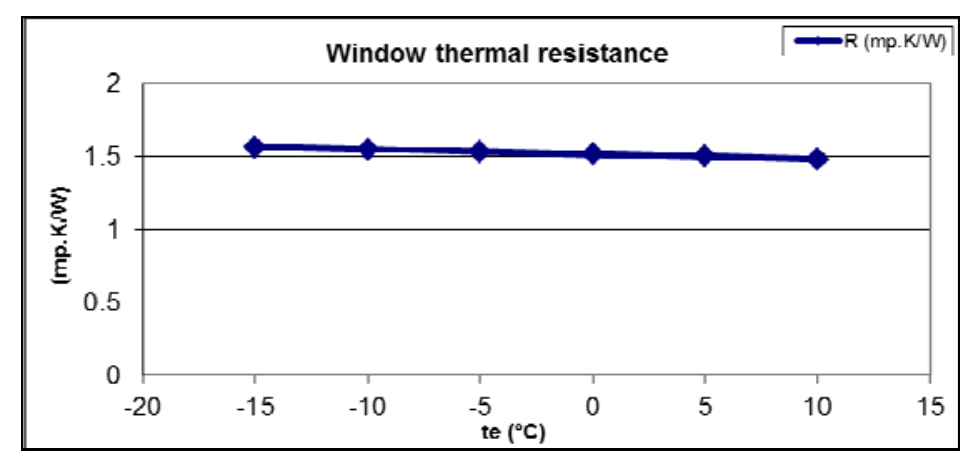

Fig. 4

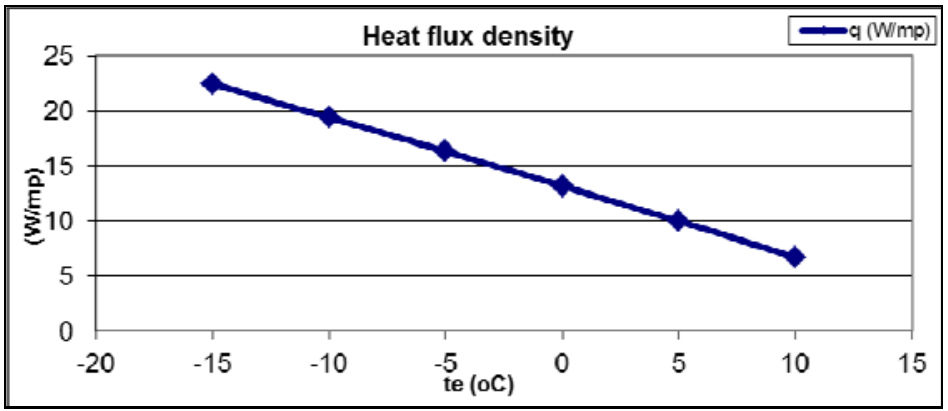

Fig. 5

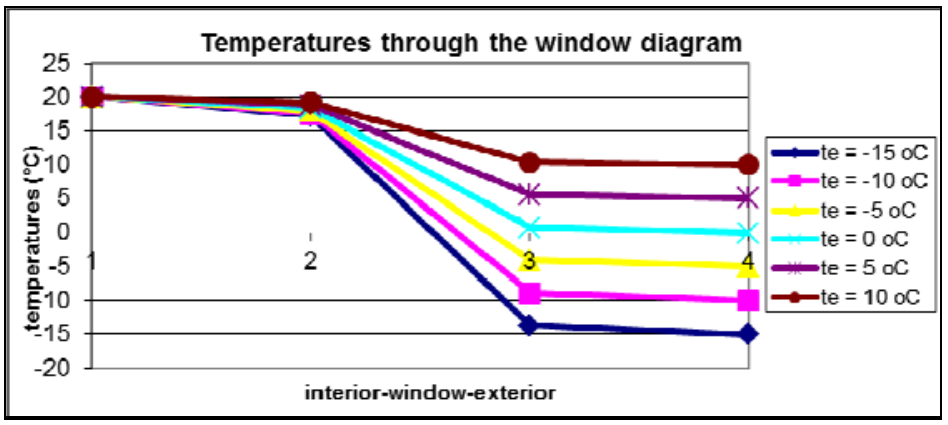

Fig. 6

Case B, unlike A, has introduced two changes, namely the gas became Krypton and one of the coefficients of emissivity became 0.1 . The results were: an increase of approx. 4 times for the thermal resistance of the window and thus a considerable decrease in the density of the dissipated heat flux through the window. Changes occurred in terms of temperature diagram but at a much smaller scale.

C. Double glazed window: te $=0{ }^{\circ} \mathrm{C} ; \delta=0.02 \mathrm{~m} ; \varepsilon_{1}=\varepsilon_{2}=0.9$

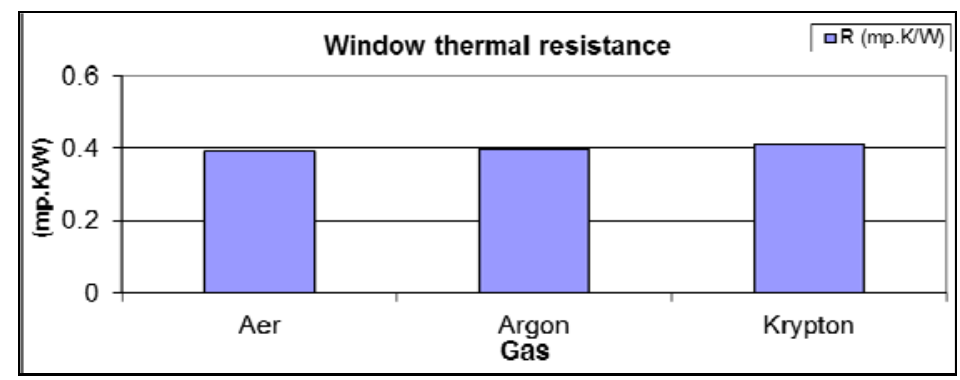

Fig. 7 
As shown in Fig. 7 the type of gas has a relative importance on the thermal resistance of the window, actually not a very big one.

D. Double glazed window: $t_{e}=0{ }^{\circ} \mathrm{C} ; \delta=0.02 \mathrm{~m} ;$ gas $=$ Krypton

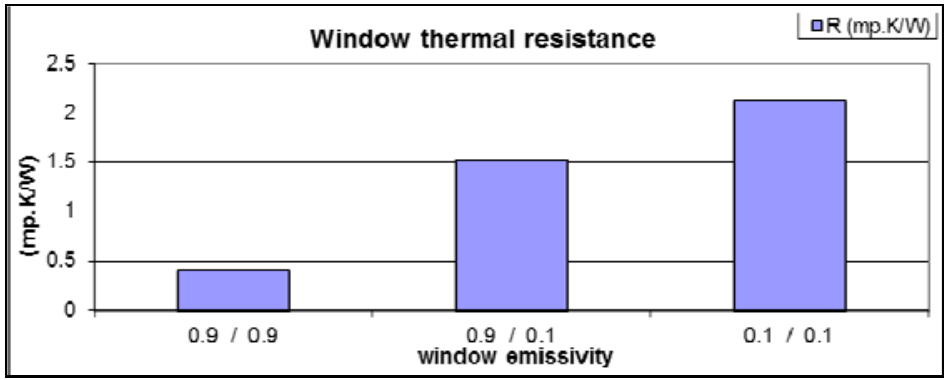

Fig. 8

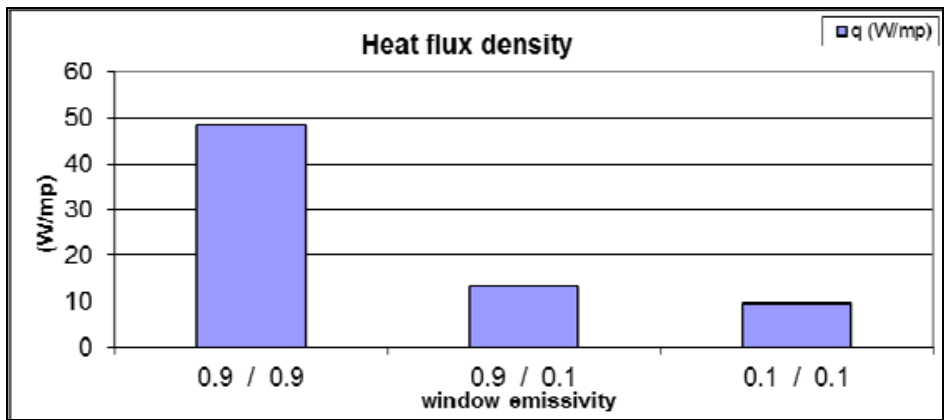

Fig. 9

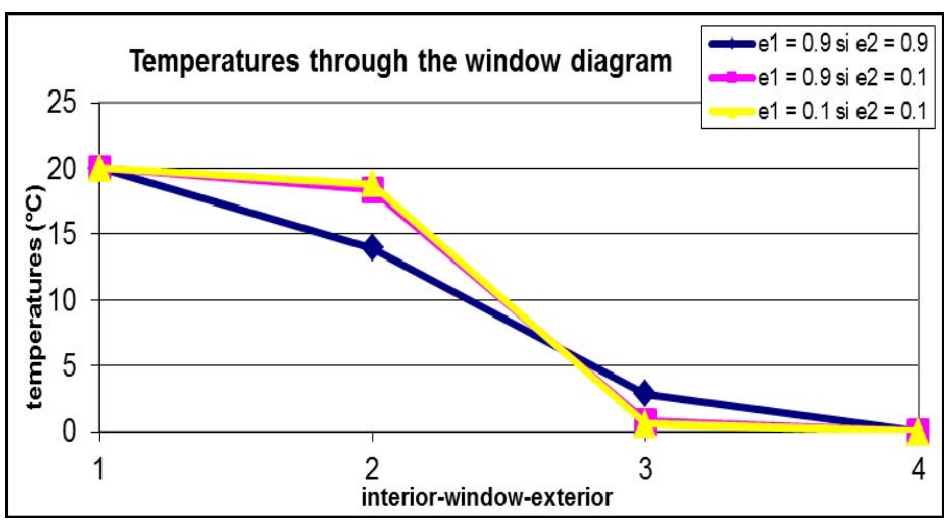

Fig. 10

Reduction of transparent element surface emissivity leads to:

- important increase of thermal resistance of the window (see Fig. 8);

- significant reduction of heat flux density (see Fig. 9);

- temperature diagram confirms an increased temperature drop between transparent elements (see Fig. 10);

E. Double glazed window: gas $=$ air, $t_{e}=0{ }^{\circ} \mathrm{C}, e_{1}=e_{2}=0.9$

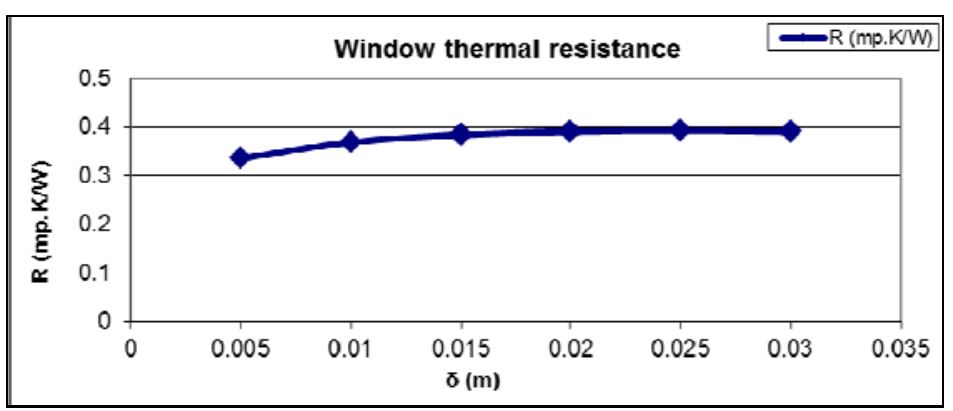

Fig. 11 


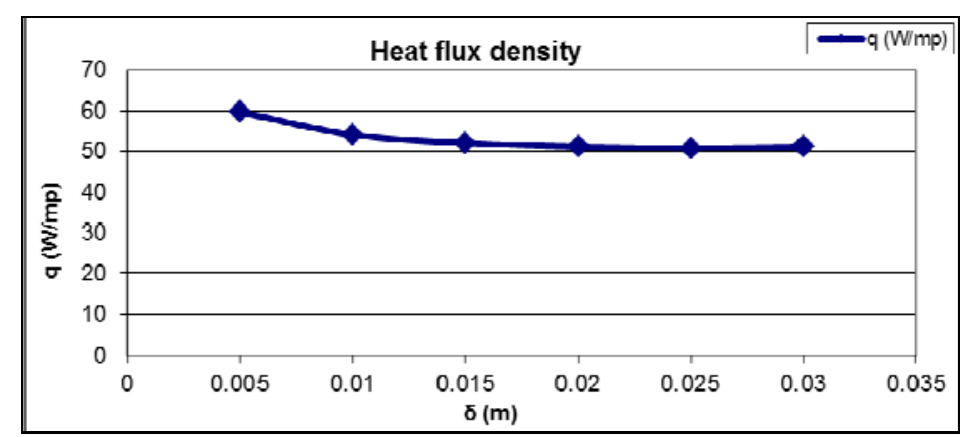

Fig. 12

The analysis by the distance between the transparent elements reveals a weak variation of the thermal resistance of the window with this parameter. It results that the distance between $1 \mathrm{~cm}$ and $2 \mathrm{~cm}$ is better to be used.

Triple glazed window case.

F. Triple glazed window: gas $=$ air $; \delta_{12}=\delta_{23}=0.02 \mathrm{~m} ; \varepsilon_{1}=\varepsilon_{2}=\varepsilon_{3}=0.9$

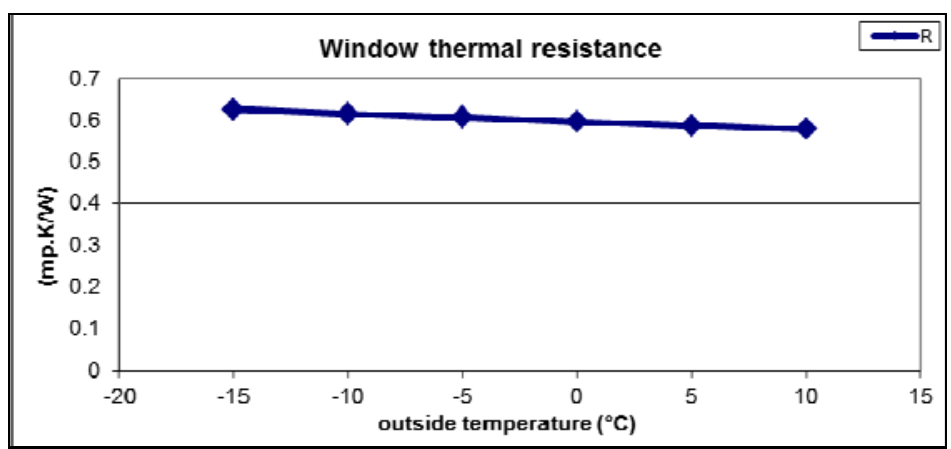

Fig. 13

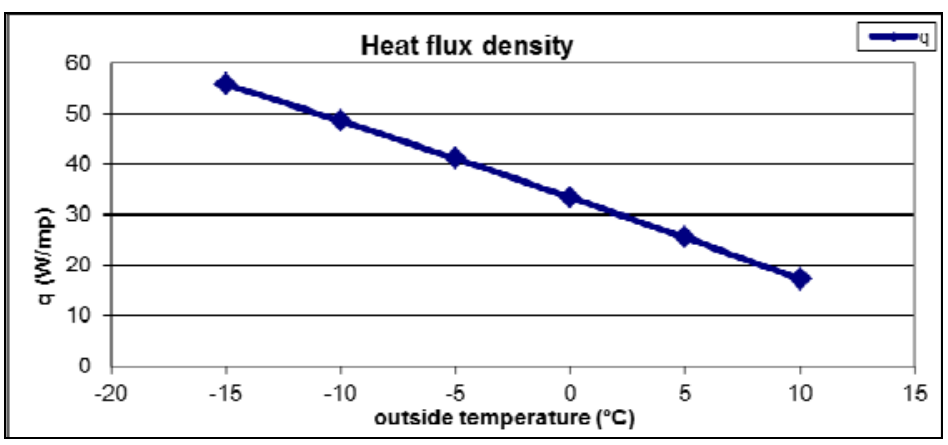

Fig. 14

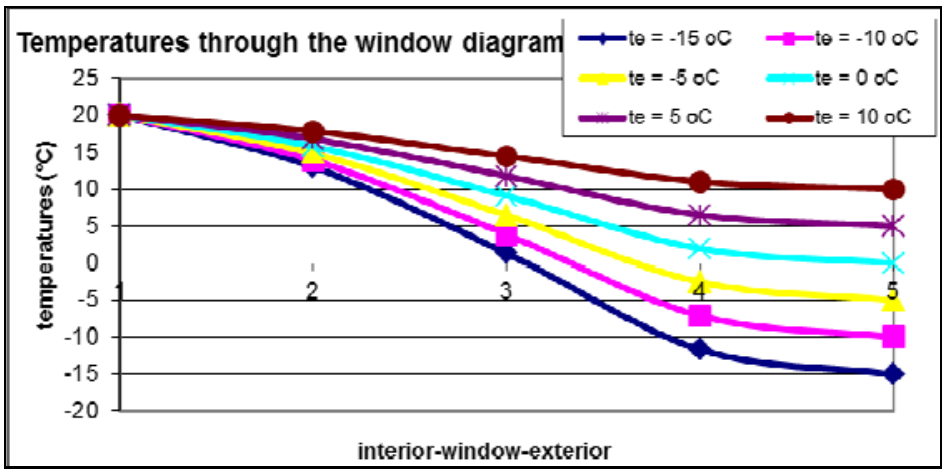

Fig. 15

Fig. 11 certifies just as with the double glazed window an almost constant value of the thermal resistance of the triple glazed window depending on the outside temperature. However, the heat 
flux density decreases considerably with the outside temperature increase and the temperature diagram has a shape similar to the one corresponding to the double glazed window.

G. Triple glazed window: te $=0^{\circ} \mathrm{C} ; \delta_{12}=\delta_{23}=0.02 \mathrm{~m} ; \varepsilon_{1}=\varepsilon_{2}=\varepsilon_{3}=0.9$

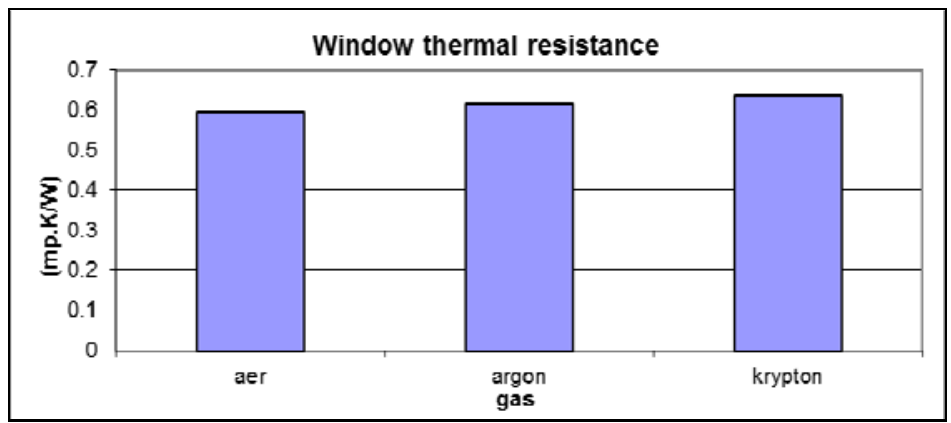

Fig. 16

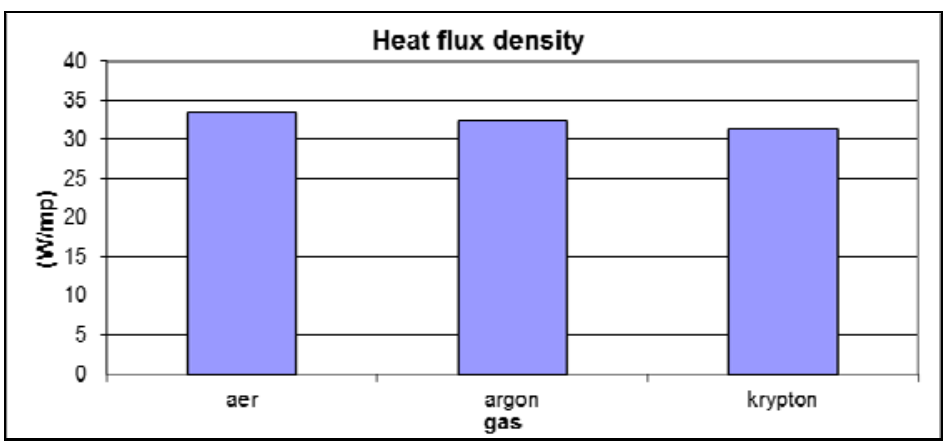

Fig. 17

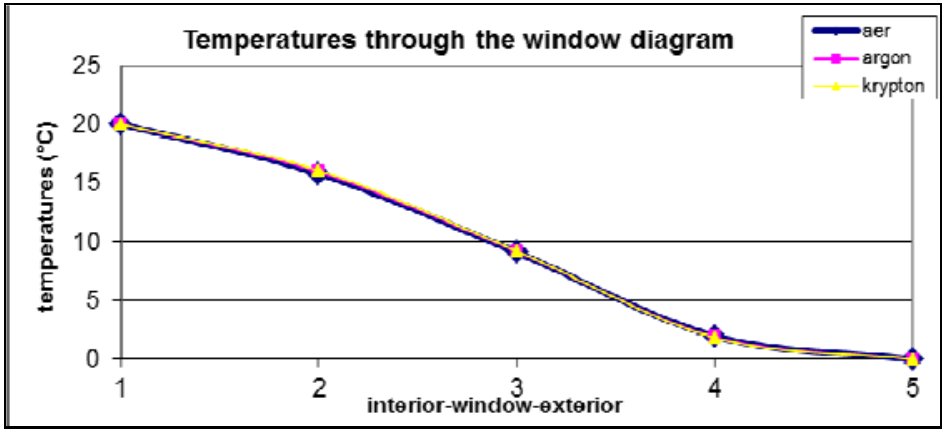

Fig. 18

As in the case of the double glazed window, in the triple glazed window case the introduction of argon or krypton leads to a not very important increase in the thermal resistance of the window and therefore to a slight decrease of the heat flux density.

$H$. Triple glazed window: gas $=$ air, $t_{e}=0^{\circ} \mathrm{C} ; \delta_{12}=\delta_{23}=0.02 \mathrm{~m}$

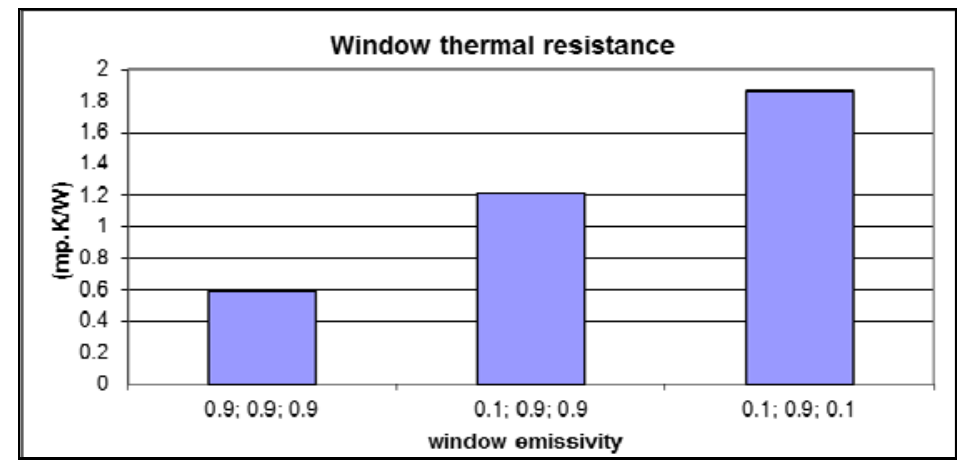

Fig. 19 


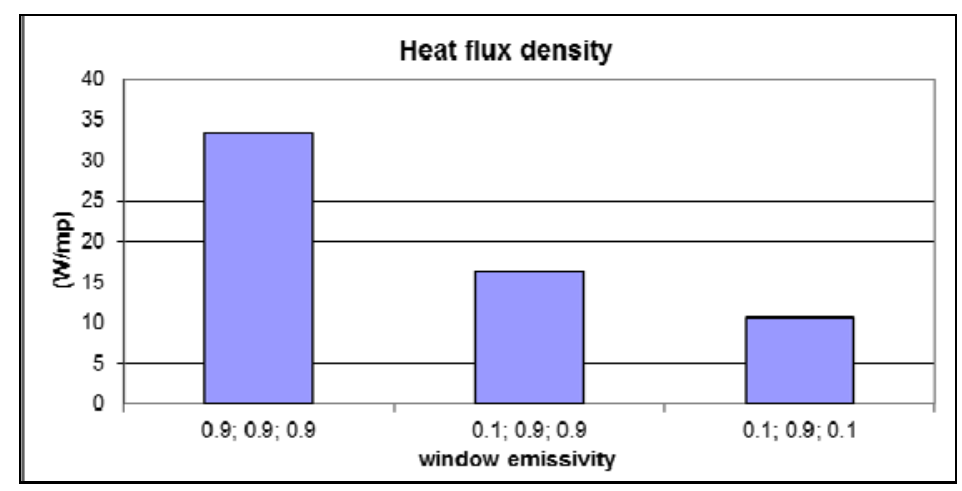

Fig. 20

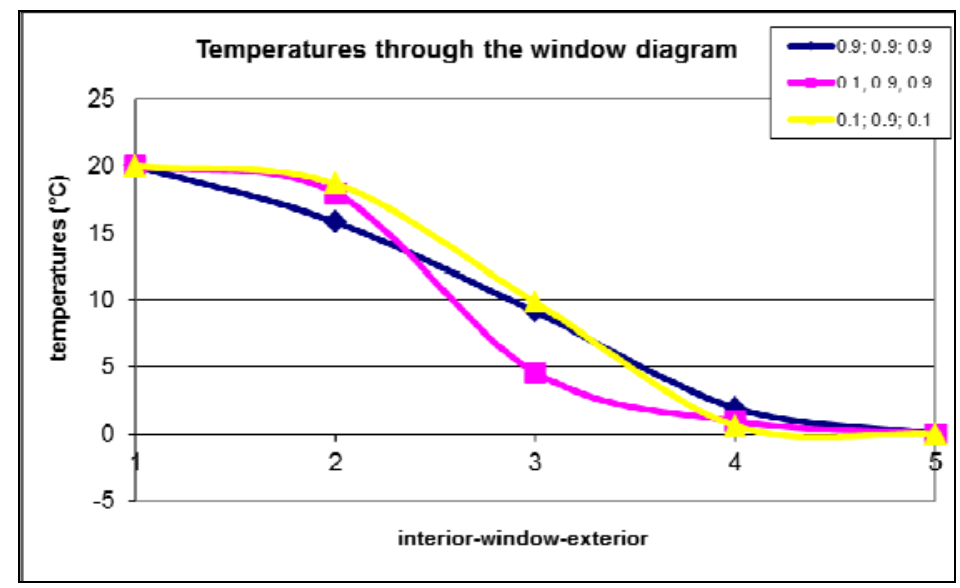

Fig. 21

The analysis considering the set of the transparent element surface emissivity leads to significant changes of the thermal resistance of the window and consequently the heat flux density. The temperature diagram undergoes certain changes but not very important ones.

An additional analysis was undertaken in terms of the thermal resistance of the triple glazed window and thermal resistance of the double glazed window.

I. Gas $=$ air; $\delta=0.02 \mathrm{~m} ; \varepsilon=0.9$ : Double glazed window - Triple glazed window

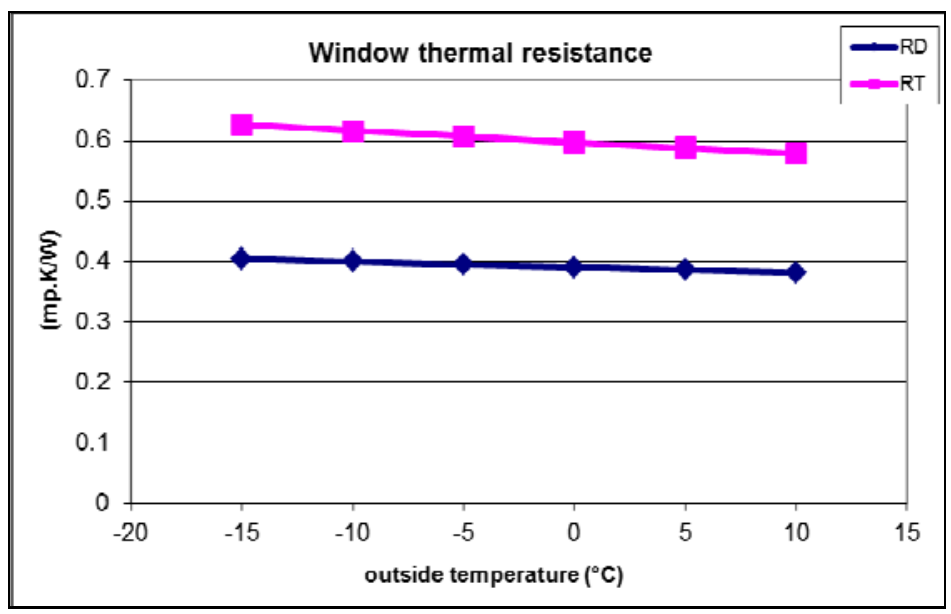

Fig. 22

As shown in Fig. 20 thermal resistance of the triple glazed window is considerably higher than its double glazed window counterpart. 


\section{Conclusions}

As mentioned at the beginning of the present paper we aim to make a theoretical analysis on the energy performance of modern double and triple glazed windows, in terms of heat transmitted through the surface.

The theoretical treatment was based on stationary heat transfer balance for each of the transparent elements involved. The theoretical work procedure and values of the physical constants corresponding to different gases used between the transparent elements and the transparent surface emissivity values involved in the processes of convective and radiant heat transfer were presented.

The determinative parameters on energy performance were analyzed: distance between transparent elements, gas type between the transparent elements and transparent element surface emissivity. The analysis was performed in different climatic stress situations from the outside environment. The results were presented numerically and graphically in order to make comparative observations on the importance of the mentioned parameters.

Generally the known values in the calculation of thermo building regulations C107 were obtained, but the present study offers the possibility of future research diversifying in this direction by introducing a wide range of transparent elements and gas components.

\section{References}

[1] Iordache, F. (2010). Termotehnica Construcțiilor. București: Ed. Matrix Rom. Ediția a 3-a.

[2] Rubin, M. (1982). Calculating heat transfer through windows. Energy Research. Vol 6.

[3] Reglementation Thermique. (2000), Regles Th-U 